\title{
Osteoderm histology of Late Pleistocene cingulates from the intertropical region of Brazil
}

Paulo Victor Luiz Gomes Da Costa Pereira, Gustavo Duarte Victer, Kleberson De Oliveira Porpino, and Lílian Paglarelli Bergqvist

Acta Palaeontologica Polonica 59 (3), 2014: 543-552 doi: http://dx.doi.org/10.4202/app.2011.0117

During the Late Pleistocene, several possibly endemic cingulate species, known mostly from isolated osteoderms, carapace fragments, and caudal tubes, coexisted in the Brazilian Intertropical Region. Here, we describe the osteoderm microstructure of Pachyarmatherium brasiliense, as well as the glyptodonts Panochthus greslebini, Panochthus jaguaribensis and Glyptotherium sp., in order to provide additional species-diagnostic characters and shed light on their evolutionary relationships. Pachyarmatherium brasiliense lacks several derived features shared by glyptodonts and pampatheres, such as extensive bone remodeling, fibers arranged in large bundles, and relatively poorly developed layers of compact bone, thus supporting its exclusion from glyptodonts as suggested by a recent cladistic study. The osteoderm histology of $P$. greslebini resembles that of other species of Panochthus (e.g., Panochthus frenzelianus). By contrast, the presence of relatively thick layers of compact bone, the configuration and size of resorption areas, the absence of randomly oriented lateral fiber bundles, and the absence of an intermediary region between the compact and trabecular bone potentially support the exclusion of Panochthus jaguaribensis from the genus. Finally, osteoderms of the Brazilian specimens of Glyptodontinae share histological features with Glyptotherium floridanus, rather than Glyptodon, thus reinforcing their assignment to Glyptotherium. These results highlight the relevance of histological osteoderm characters in cingulate systematics, ands call for further and more comprehensive studies.

Key words: Mammalia, Cingulata, Glyptodontidae, Pachyarmatherium, osteoderms, paleohistology, Pleistocene, Brazilian Intertropical Region.

Paulo V.L.D. Da Costa Pereira [paulovictor29@yahoo.com.br], Gustavo D. Victer [gvicter@gmail.com ], and Lílian P. Bergqvist [bergqvist@geologia.ufrj.br], Laboratório de Macrofosseis, Departamento de Geologia/UFRJ, Av. Athos da Silveira Ramos, 274, CCMN, Bloco G, Cidade Universitária, 21941-916, Rio de Janeiro/RJ, Brazil; Kleberson O. Porpino [kleporpino@yahoo.com.br], Laboratório de Sistemática e Ecologia Animal, Departamento de Ciências Biológicas, Universidade do Estado do Rio Grande do Norte, Rua Antônio Campos s/n, 59610-090, Mossoró/RN, Brazil. 
This is an open-access article distributed under the terms of the Creative Commons Attribution License (for details please see creativecommons.org), which permits unrestricted use, distribution, and reproduction in any medium, provided the original author and source are credited.

FaF 